\title{
Long-Term Locoregional Vascular Morbidity After Isolated Limb Perfusion and External-Beam Radiotherapy for Soft Tissue Sarcoma of the Extremity
}

\author{
Miriam L. Hoven-Gondrie, MD, ${ }^{1}$ Katja M. J. Thijssens, MD, $\mathrm{PhD},{ }^{1}$ \\ Jan J. A. M. Van den Dungen, MD, $\mathrm{PhD},{ }^{2}$ Jan Loonstra, ${ }^{2}$ \\ Robert J. van Ginkel, MD, PhD, ${ }^{1}$ and Harald J. Hoekstra, MD, $\mathrm{PhD}^{1}$
}

\footnotetext{
${ }^{1}$ Department of Surgical Oncology, University Medical Center Groningen, University of Groningen, PO Box 30.001, 9700 RB, Groningen, the Netherlands

${ }^{2}$ Departments of Vascular Surgery, University Medical Center Groningen, University of Groningen, PO Box 30.001, 9700 RB, Groningen, the Netherlands
}

\begin{abstract}
Background: Isolated limb perfusion (ILP) with tumor necrosis factor alpha (TNF- $\alpha$ ) and melphalan, followed by delayed surgical resection and adjuvant external-beam radiotherapy is a limb salvage treatment strategy for locally advanced soft tissue sarcomas. The long-term vascular side effects of this combined procedure were evaluated.

Methods: Thirty-two patients were treated for a locally advanced sarcoma of the upper $(\mathrm{n}=5)$ or lower limb $(\mathrm{n}=27)$. All patients underwent a noninvasive vascular work-up.

Results: Five patients underwent a leg amputation, in two cases due to critical leg ischemia 10 years after ILP. With a median follow-up of 88 (range, 17-159) months, none of the patients with a salvaged lower leg $(n=22)$ experienced peripheral arterial occlusive disease. Ankle-brachial index (ABI) measurements in the involved leg (median, 1.02; range, .50-1.20) showed a significant decrease compared with the contralateral leg (median, 1.09; range, .91$1.36, P=.001)$. Pulsatility index (PI) was decreased in the treated leg in 17 of 22 patients at the femoral level (median, 6.30; range, $2.1-23.9$ vs. median, 7.35 ; range, $4.8-21.9 ; P=.011$ ) and in 19 of 20 patients at popliteal level (median, 8.35; range, 0-21.4 vs. median, 10.95; range, 8.0-32.6; $P<.0005)$. In patients with follow-up of $>5$ years, there was more often a decrease in ABI $(P=.024)$ and PI at femoral level $(P=.011)$.

Conclusions: ILP followed by resection and external-beam radiotherapy can lead to major late vascular morbidity that requires amputation. Objective measurements show a time-related decrease of ABI and femoral PI in the treated extremity.
\end{abstract}

Key Words: Sarcoma-Perfusion-Radiation-Vascular-Complications.

Optimum treatment strategies for locally advanced soft tissue sarcoma (STS) of the extremities have evolved considerably over the past 25 to 30 years. In

Received June 3, 2006; accepted November 27, 2006; published online: April 25, 2007.

Presented at the 59th Annual Cancer Symposium, Society of Surgical Oncology, San Diego, CA, 2006.

Address correspondence and reprint requests to: Harald J. Hoekstra, MD, PhD; E-mail: h.j.hoekstra@chir.umcg.nl

Published by Springer Science+Business Media, LLC $\odot 2007$ The Society of Surgical Oncology, Inc.
1982, Rosenberg et al. ${ }^{1}$ showed that amputations or exarticulations of the affected limb do not result in higher survival rates. This made preservation of the extremity and good limb function all the more important. ${ }^{2,3}$ An established limb salvage strategy is to perform a hyperthermic isolated limb perfusion (ILP) with tumor necrosis factor alpha (TNF- $\alpha$ ) and melphalan, followed by delayed tumor resection and, in case of marginal or nonradical resection, by adjuvant external-beam radiotherapy $\left(\right.$ EBRT) ${ }^{4,5} \mathrm{Al}-$ 
though ILP, in which high doses of chemotherapy are regionally delivered, is a technically demanding operative procedure, amputation necessitated by peri- or postoperative surgical complications occurs in $<1 \%$ of cases. ${ }^{4}$ On the other hand, patients undergoing an intentionally limb-saving treatment with ILP still have a short- or long-term risk up to $40 \%$ of loss of the affected limb due to massive necrosis of the tumor and overlying skin resulting in a soft tissue deficit, late local recurrence, or critical leg ischemia. $^{5}$

In ILP, cytotoxic agents are used, which cause a local toxic effect in the perfused extremity. After investigation of several perfusion agents for STS, the two-drug regimen of TNF- $\alpha$ and melphalan turned out to be highly effective. ${ }^{4}$ The pathological tumor microvascularization is the primary target for TNF$\alpha$, resulting in coagulative and hemorrhagic necrosis of the tumors. ${ }^{6}$ Olieman et al. $^{7}$ demonstrated by angiography findings of specific destruction of tumor vessels after perfusion with TNF- $\alpha$, leaving the normal vasculature unchanged. The surgical procedure of ILP, however, exposes the cannulated blood vessels to intravascular manipulation, by means of arteriotomy, venotomy, and the insertion of catheters. Consequently, a $1 \%$ to $10 \%$ risk of developing acute vascular complications, such as thrombosis at the arteriotomy site and deep-vein thrombosis (DVT), has been described in the literature. ${ }^{8-10}$ Moreover, chemotherapy and atherosclerosis risk factors could have a synergistic role on the development of arterial stenosis. ${ }^{11}$ Adjuvant EBRT leads to a high incidence of early and late morbidity. Long-term vascular side effects, in particular arterial stenosis, can be induced by radiotherapy. ${ }^{12-14}$

Because little is known with respect to the late vascular morbidity of the combined procedure of ILP and EBRT, a retrospective study was conducted to evaluate the long-term locoregional vascular side effects of ILP, followed by delayed surgical resection and adjuvant high-dose EBRT.

\section{PATIENTS AND METHODS}

From 1991 to 2003, a total of 73 patients with a median age of 54 (range, 14-80) years and with locally advanced STS underwent 77 perfusions with a combination of TNF- $\alpha$ and melphalan, with $(\mathrm{n}=19)$ or without $(\mathrm{n}=58)$ interferon gamma at the Division of Surgical Oncology of the University Medical Center Groningen, University of Groningen. The perfusion technique has been previously exten- sively described. ${ }^{15,16}$ Perfusion was followed by delayed local resection of the tumor remnant, and in cases of marginal or microscopically positive resection margins, high-dose postoperative EBRT was considered.

In 2005, 39 patients were still alive and in followup. Information about their past and current oncological and vascular status was obtained from the follow-up notes in the medical records. Seven patients were unable to participate in the study because of severe or advanced morbidity or comorbidity $(\mathrm{n}=2)$ or because of nonmedical reasons $(\mathrm{n}=5)$. Consequently, 32 patients, 14 men (44\%) and 18 women (56\%), with a median age of 47 (range, 14-71) years, were included (response rate, $82 \%$ ). They completed a vascular checklist that asked questions about their medical vascular history, and they were screened for risk factors of vascular disease, such as smoking, hypertension, and diabetes. A blood sample was drawn to determine the cholesterol spectrum, which was used as an indicator of risk for atherosclerosis. All patients underwent a noninvasive arterial and venous vascular work-up that comprised duplex ultrasonography and vascular pressure measurements. The ankle-brachial index (ABI) and pulsatility index (PI), which are indications of vascular blood flow velocity, were measured to indicate the arterial status of the limb. For evaluation of veins, ultrasonography was performed to detect DVT and insufficiency. All investigations were performed by the same examiner (J.L.).

Five patients had a STS of the upper extremity $(16 \%)$ treated with axillary perfusion. The remaining 27 patients had a STS located in the lower limb (84\%) and were treated with iliac $(\mathrm{n}=13,41 \%)$, femoral $(\mathrm{n}=5,16 \%)$, or popliteal $(\mathrm{n}=9,28 \%)$ perfusion. There were 27 primary STS and 5 recurrent STS. Twenty-four patients (75\%) received adjuvant 60 to 70 Gy EBRT in fractions of $2 \mathrm{~Gy}$. Adjuvant systemic chemotherapy was provided to seven patients. Definite histopathological classification of tumor (one embryonal rhabdomyosarcoma and one extraossal osteosarcoma) was the reason in two patients; three patients were treated with chemotherapy because they participated in an European Organization for the Research and Treatment of Cancer trial (EORTC 62931). Two patients received chemotherapy in a palliative setting for distant metastasis. All patients were treated after informed consent was obtained according to institutional guidelines. Twelve different histological types of STS were distinguished. The pathological grade of the tumor was scored following the criteria 
of Coindre et al., ${ }^{17}$ and the stage of the tumor was assigned according to the American Joint Committee on Cancer. ${ }^{18}$ Patient and tumor characteristics are summarized in Table 1.

The results were statistically analyzed by the Wilcoxon rank test and the Mann-Whitney U-test. Values of $P \leq .05$ were considered significant. SPSS 12.0.1 for Windows statistical software was used (SPSS, Chicago, IL).

\section{RESULTS}

Before ILP, none of the patients had a history of cerebrovascular insufficiency, coronary artery disease, peripheral arterial occlusive disease, or any other vascular disease. Risk factors for cardiovascular disease, hypertension, diabetes, smoking, obesity, hypercholesterolemia, and familiar arterial occlusive disease were analyzed (Table 2).

Two patients underwent vascular reconstruction after en-bloc tumor resection with the artery. One patient underwent a reconstruction of the femoral artery with an infragenual femoral-popliteal bypass, and the second patient underwent a popliteal artery reconstruction with an autologous vein graft. A DVT in the lower leg was diagnosed in the postoperative period in three patients $(7.7 \%)$.

Nine $(23 \%)$ of the 39 alive patients underwent a lower limb amputation at different levels after ILP with or without EBRT. No amputations of the upper extremity were performed. In two patients with microscopically involved resection margins, an amputation of the affected limb was indicated because adjuvant radiotherapy was contraindicated. One patient underwent amputation due to tumor recurrence 18 months after ILP and EBRT. Amputation was performed for critical leg ischemia due to atherosclerosis in two patients at 110 and 125 months after ILP and EBRT. Because of severe obstruction of the crural vessels, reconstructive therapy was not suitable.

The other four amputations were performed for extensive postperfusion necrosis of the involved tumor site (three patients at 0,8 , and 12 months after ILP with or without EBRT) and arterial occlusion without any vascular reconstructive possibilities (one patient 15 months after ILP and EBRT).5[A1] Figure 1 illustrates treatment, outcome, and reasons for amputation. Five of the 32 patients included in this study underwent amputation and could therefore only partially undergo vascular follow-up.

\section{Arterial Vascular Disease}

With a median follow-up of 88 (range, 17-159) months, no patient experienced peripheral arterial occlusive disease. With duplex ultrasonography, however, two patients showed a complete arterial occlusion at the level of cannulation (6\%). One of them underwent an iliac perfusion and EBRT because of a STS of the lower leg in 1993. After 10 years, she had signs of critical leg ischemia, which required a transfemoral amputation. She is now free of pain and can walk with a well-functioning prothesis. The other patient showed an axillary occlusion 10 years after an axillary perfusion, followed by resection and EBRT at the forearm. She did not have any symptoms of arterial occlusive disease, and her arm functions normally. Duplex ultrasonography showed good collateral flow. Two other patients (6\%) showed an arterial stenosis at cannulation level at 22 and 30 months after axillary perfusions, followed by EBRT at the upper arm and axilla in one and systemic chemotherapy in both patients. They had normal arm function without any signs of ischemia.

The arteries at resection level were also evaluated. One patient with a fossa poplitea STS had complete occlusion of the superficial femoral artery 6 years after ILP and EBRT, with open arteries below knee level. A femoral-popliteal bypass was considered but was not performed because of the absence of any symptoms. At the time of evaluation, the ABI was .50; the patient did not have any complaints besides compression ulcers on his feet, which responded well to conservative therapy. The patient who needed an autologous vein graft of the popliteal artery has a stenosis at this level without clinical signs of arterial occlusive disease.

Twenty-two of the total 32 patients included underwent ABI measurements; 22 had their PI determined at the femoral level and 20 at the popliteal level. Five patients were excluded because of amputation of the limb; another five were excluded because of a STS located in the upper limb. Of the remaining 22 patients, 18 received postoperative EBRT for the above-described indications.

In 21 of 22 patients, the ABI (normal, $\geq 1.00$ ) in the treated leg was .91 or more. As mentioned above, one patient had an ABI of .50 without any complaints. ABI measurements in the involved leg (median, 1.02; range, .50-1.20) showed a significant decrease compared with the contralateral leg (median, 1.09; range, $.91-1.36 ; P=.001)$. Seven patients showed a decreased femoral PI (normal range, 5-10). Six of them underwent an iliac perfusion (86\%). Popliteal PI (normal range, 6-12) was decreased in six patients. 
TABLE 1. Characteristics of patients

\begin{tabular}{|c|c|c|c|c|c|c|c|c|c|c|}
\hline Age (y) & Sex & Disease & Localization & Histology & Grade & $\begin{array}{l}\text { AJCC } \\
\text { stage }\end{array}$ & Level & EBRT & Amputation & $\begin{array}{l}\text { Follow-up } \\
\text { (mo) }\end{array}$ \\
\hline 18 & $\mathrm{~F}$ & Primary & Upper leg & Embryonal rhabdomyosarcoma & 3 & 3 & Iliac & $\mathrm{N}$ & $\mathrm{N}$ & 159 \\
\hline 44 & $\mathrm{~F}$ & Recurrent & Popliteal fossa & Myxoid liposarcoma & 1 & 1 & Iliac & $\mathrm{Y}$ & $\mathrm{N}$ & 152 \\
\hline 43 & M & Primary & Upper leg & Synovial sarcoma & 3 & 3 & Iliac & $\mathrm{Y}$ & $\mathrm{N}$ & 151 \\
\hline 18 & M & Primary & Lower leg & Myxoid chondrosarcoma & 2 & 3 & Popliteal & $\mathrm{Y}$ & $\mathrm{Y}$ & 149 \\
\hline 48 & $\mathrm{~F}$ & Primary & Upper leg & Well differentiated liposarcoma & 1 & 1 & Iliac & $\mathrm{Y}$ & $\mathrm{N}$ & 143 \\
\hline 56 & $\mathrm{~F}$ & Primary & Proximal tibia & PNET & 3 & 3 & Iliac & $\mathrm{Y}$ & $\mathrm{Y}$ & 137 \\
\hline 50 & $\mathrm{~F}$ & Recurrent & Foot & PUS & 3 & 3 & Popliteal & $\mathrm{N}$ & $\mathrm{N}$ & 135 \\
\hline 25 & $\mathrm{~F}$ & Primary & Popliteal fossa & Synovial sarcoma & 2 & 3 & Popliteal & $\mathrm{Y}$ & $\mathrm{N}$ & 132 \\
\hline 44 & M & Primary & Upper leg & Myxoid liposarcoma & 1 & 1 & Iliac & $\mathrm{Y}$ & $\mathrm{N}$ & 131 \\
\hline 24 & M & Recurrent & Lower leg & Synovial sarcoma & 2 & 3 & Popliteal & $\mathrm{Y}$ & $\mathrm{N}$ & 129 \\
\hline 37 & $\mathrm{~F}$ & Primary & Elbow & MPNST & 2 & 3 & Axillary & $\mathrm{Y}$ & $\mathrm{N}$ & 121 \\
\hline 48 & M & Primary & Popliteal fossa & Myxoid liposarcoma & 2 & 3 & Iliac & $\mathrm{Y}$ & $\mathrm{N}$ & 111 \\
\hline 63 & $\mathrm{~F}$ & Recurrent & Lower leg & PÜS & 2 & 3 & Popliteal & $\mathrm{N}$ & $\mathrm{Y}$ & 107 \\
\hline 37 & $\mathrm{M}$ & Primary & Upper leg & Myxoid liposarcoma & 1 & 1 & Iliac & $\mathrm{Y}$ & $\mathrm{N}$ & 105 \\
\hline 58 & M & Primary & Upper leg & PÜS & 2 & 3 & Iliac & $\mathrm{Y}$ & $\mathrm{N}$ & 98 \\
\hline 71 & $\mathrm{~F}$ & Primary & Upper leg & Leiomyosarcoma & 1 & 1 & Femoral & $\mathrm{N}$ & $\mathrm{N}$ & 94 \\
\hline 45 & $\mathrm{~F}$ & Primary & Upper leg & PUS & 3 & 3 & Iliac & $\mathrm{N}$ & $\mathrm{N}$ & 82 \\
\hline 56 & $\mathrm{~F}$ & Primary & Lower leg & PUS & 3 & 3 & Popliteal & $\mathrm{Y}$ & $\mathrm{N}$ & 61 \\
\hline 63 & M & Primary & Popliteal fossa & Myxoid chondrosarcoma & & 3 & Femoral & $\mathrm{Y}$ & $\mathrm{N}$ & 50 \\
\hline 37 & $\mathrm{~F}$ & Primary & Knee & Leiomyosarcoma & 1 & 1 & Femoral & $\mathrm{Y}$ & $\mathrm{N}$ & 36 \\
\hline 28 & $\mathrm{M}$ & Primary & Popliteal fossa & Synovial sarcoma & 2 & 3 & Femoral & $\mathrm{Y}$ & $\mathrm{N}$ & 36 \\
\hline 57 & $\mathrm{~F}$ & Primary & Upper leg & PUS & 3 & 3 & Femoral & $\mathrm{Y}$ & $\mathrm{N}$ & 35 \\
\hline 42 & $\mathrm{~F}$ & Primary & Knee & Synovial sarcoma & 2 & 3 & Iliac & $\mathrm{Y}$ & $\mathrm{Y}$ & 32 \\
\hline 47 & $\mathrm{~F}$ & Primary & Arm & PUS & 3 & 3 & Axillary & $\mathrm{Y}$ & $\mathrm{N}$ & 30 \\
\hline 58 & $\mathrm{~F}$ & Primary & Lower leg & PUS & 3 & 3 & Popliteal & $\mathrm{Y}$ & $\mathrm{N}$ & 26 \\
\hline 27 & M & Primary & Arm & Epithelioid sarcoma & 3 & 4 & Axillary & $\mathrm{Y}$ & $\mathrm{N}$ & 26 \\
\hline 71 & M & Recurrent & Arm & Myxoid fibrosarcoma & 1 & 1 & Axillary & $\mathrm{N}$ & $\mathrm{N}$ & 24 \\
\hline 56 & $\mathrm{~F}$ & Primary & Arm & Extraosseal osteosarcoma & 3 & 3 & Axillary & $\mathrm{N}$ & $\mathrm{N}$ & 22 \\
\hline 14 & $\mathrm{M}$ & Primary & Lower leg & PUS & 3 & 3 & Popliteal & $\mathrm{Y}$ & $\mathrm{N}$ & 20 \\
\hline 65 & $\mathrm{~F}$ & Primary & Foot & Synovial sarcoma & 2 & 3 & Popliteal & $\mathrm{N}$ & $\mathrm{Y}$ & 18 \\
\hline 63 & M & Primary & Upper leg & Synovial sarcoma & 3 & 3 & Iliac & $\mathrm{Y}$ & $\mathrm{N}$ & 17 \\
\hline 71 & M & Primary & Upper leg & Rhabdomyosarcoma & 3 & 3 & Iliac & $\mathrm{Y}$ & $\mathrm{N}$ & 17 \\
\hline
\end{tabular}

AJCC, American Joint Committee on Cancer; EBRT, external-beam radiotherapy; PNET, primitive neuroectodermal tumor; PUS, pleomorphic undifferentiated sarcoma; MPNST, malignant peripheral nerve sheath tumor.

TABLE 2. Risk factors for atherosclerosis

\begin{tabular}{lrrl}
\hline Risk factor & $\mathrm{n}$ & $\%$ & $\begin{array}{l}\text { Dutch population } \\
(\%)\end{array}$ \\
\hline Hypertension & 10 & 31 & $9.9^{a, b}$ \\
Diabetes mellitus & 4 & 13 & $3.1^{b}$ \\
Smoking & & & $29.6^{b}$ \\
$\quad$ Smokers & 9 & 28 & \\
$\quad$ Former smokers & 10 & 31 & \\
BMI & & & \\
$\quad$ BMI > 25.0 & 17 & 53 & $46.5^{b}$ \\
$\quad$ BMI > 30.0 & 4 & 13 & $10.9^{b}$ \\
$\quad$ Hypercholesterolemia & 6 & 19 & $14^{c}$ \\
$\quad$ total cholesterol > 6.5) & & & \\
Familiar cardiovascular disease & 14 & 44 & NA \\
\hline
\end{tabular}

BMI, body mass index; NA, not available.

${ }^{a}$ Range, $5 \%$ to $45 \%$.

${ }^{b}$ From http://www.cbs.nl/.

${ }^{c}$ From http://www.hartstichting.nl/.

Perfusion at a more proximal level was performed in four of these patients (67\%). When compared with the contralateral leg, PI was lower in the treated leg in 17 of 22 patients at femoral level (median, 6.30; range, 2.1-23.9 vs. median, 7.35; range, 4.8-21.9;
$P=.011)$ and in 19 of 20 patients at popliteal level (median, 8.35; range, 0-21.4, vs. median, 1.95; range, 8.0-32.6; $P<.0005$ ) (Table 3). There were no differences in objective vascular side effects between men and women, between patients who did or did not undergo EBRT, or between patients $<50$ years old versus older patients (Table 4). In patients with a follow-up period of $>5$ years, there was more often a decrease in ABI, compared with patients with shorter follow-up (13 of 14 patients vs. 4 of 8 patients, $P=$.024). With a longer follow-up period, there was also more often a decrease in PI at the femoral level (13 of 14 patients vs. 3 of 7 patients, $P=.024$ ), but not at the popliteal level (12 of 12 patients vs. 7 of 8 patients, $P=.221$ ) (Table 5). No patient required vascular intervention during follow-up.

\section{Venous Vascular Disease}

Many patients had some symptoms of venous insufficiency, such as lower limb pain, feelings of 


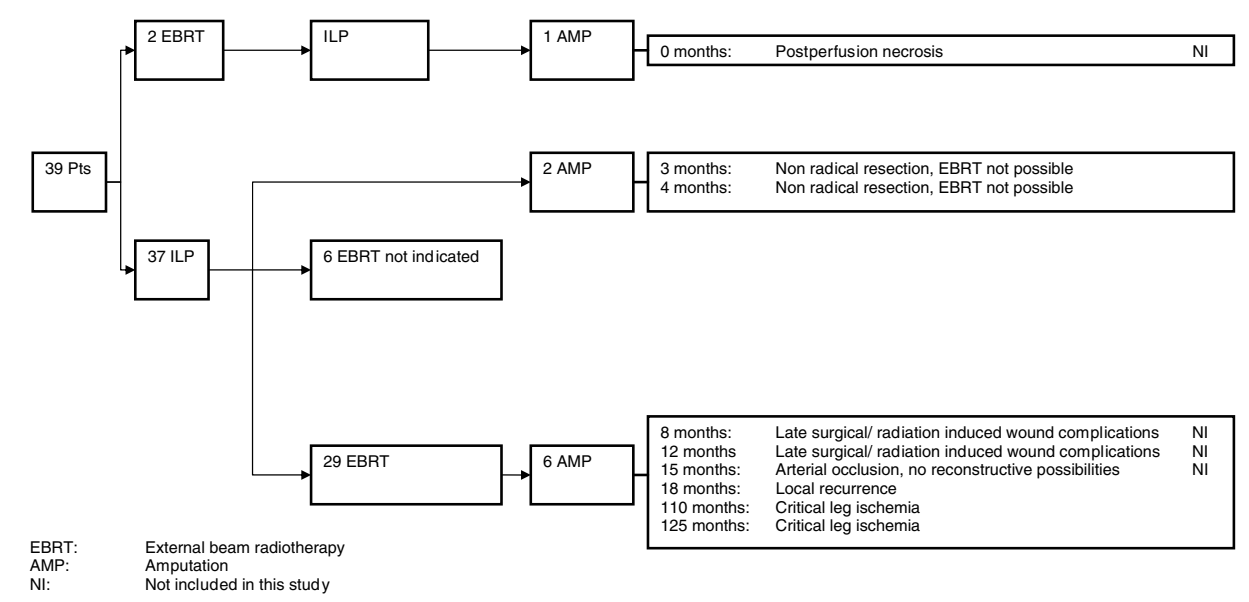

FIG. 1. Flow chart illustrating treatment, outcome, and reasons for amputation. EBRT, external-beam radiotherapy; AMP, amputation; NI, not included in this study.

TABLE 3. Results of ankle-brachial index (ABI) and pulsatility index (PI) measurements in lower extremities of 22 patients

\begin{tabular}{lllr}
\hline & $\begin{array}{l}\text { Treated extremity, } \\
\text { median (range) }\end{array}$ & $\begin{array}{l}\text { Contralateral extremity, } \\
\text { median (range) }\end{array}$ & $P$ value \\
\hline ABI & $1.02(.50-1.20)$ & $1.090(.91-1.36)$ & .001 \\
PI femoral & $6.30(2.1-23.9)$ & $7.35(4.8-21.9)$ & .011 \\
PI popliteal & $8.35(.0-21.4)$ & $10.95(8.0-32.6)$ & $<.0005$ \\
\hline
\end{tabular}

heaviness and discomfort, night palsies, paresthesia, and edema. One patient (3\%) wore compression stockings because of superficial vena saphena magna insufficiency, and one patient (3\%) had unilateral superficial varicosis in the treated leg. Another three patients (9\%) showed uni- or bilateral deep insufficient venous vasculature by duplex ultrasonography, which in all cases was located at the level of resection. One DVT (3\%) and one partial venous obstruction $(3 \%)$ were found, both at the resection level. Venous vascular obstruction was not seen at the level of cannulation.

\section{DISCUSSION}

ILP with TNF- $\alpha$ and melphalan, with or without adjuvant EBRT, has become an approved treatment strategy for locally advanced STS of the extremities after the publication of the results of an European multicenter trial performed in the 1990s. ${ }^{4}$ Because our center was one of the first to use this treatment modality, we now have had more than 10 years' experience of ILP used to treat STS. This gives us the opportunity to evaluate the long-term treatment-re- lated morbidity. Critical leg ischemia approximately 10 years after ILP, necessitating amputation in two patients, led to an interest of analyzing the vascular complications of ILP with or without EBRT. ${ }^{5}$

Despite a complete destruction of tumor vasculature, ILP does not seem to have any effect on the macrovasculature of the perfused limb. ${ }^{7,20}$ However, because atherosclerosis risk factors and chemotherapy could play a synergistic role in the progression of arterial stenosis, patients who already have severe atherosclerotic disease are less suitable for ILP. ${ }^{11,19,20}$

In our study, many patients had one or more risk factors for atherosclerosis. In the study population, there seemed to be more patients with diabetes or hypercholesterolemia than in the standard Dutch population. The smoking rate is similar (28\% vs. $30 \%$ ); however, another $31 \%$ used to smoke (Table 2).

Acute vascular complications after ILP have been described in the literature. Deep-vein thrombosis (DVT) occurs in $1.7 \%$ to $10 \%$ of cases in the immediate postoperative period. ${ }^{10}$ In our studies, three patients $(7.7 \%)$ had a successfully treated DVT after ILP. DVT seems to be extremely difficult to diagnose because the postoperative effects of ILP itself-a warm, swollen edematous limb-mask the classical symptoms. To prevent this undesired complication, anticoagulant therapy is recommended. Thrombosis at the arteriotomy site has also been mentioned in earlier studies. It was not encountered in this study but should be treated by prompt trombectomy. ${ }^{9,21}$ In case of repeated ILP in the same limb, perfusion through more proximal arterial and venous sites is recommended because fibrosis at the previous oper- 
TABLE 4. P values of differences between subgroups in decrease of ankle-brachial index (ABI) and pulsatility index (PI) for 22 patients

\begin{tabular}{|c|c|c|c|c|c|c|c|c|}
\hline \multirow[b]{2}{*}{ Characteristic } & \multicolumn{2}{|c|}{ Sex } & \multicolumn{2}{|c|}{$\begin{array}{c}\text { Follow-up after } \\
\text { EBRT }\end{array}$} & \multicolumn{4}{|c|}{ Age } \\
\hline & $\mathrm{F}$ & $\mathrm{M}$ & Yes & No & $>5 \mathrm{y}$ & $<5 \mathrm{y}$ & $<50 \mathrm{y}$ & $>50 \mathrm{y}$ \\
\hline No. of patients & 11 & 11 & 18 & 4 & 14 & 8 & 13 & 9 \\
\hline $\mathrm{ABI}$ & .619 & .241 & .024 & .963 & - & - & - & - \\
\hline PI femoral decrease & .619 & .907 & .024 & .963 & - & - & - & - \\
\hline PI popliteal decrease & .269 & .937 & .221 & .414 & - & - & - & - \\
\hline
\end{tabular}

EBRT, external-beam radiotherapy.

TABLE 5. Differences in decreases in measurements according to length of follow-up

\begin{tabular}{llll}
\hline & \multicolumn{2}{c}{ Follow-up, n $(\%)$} & \\
\cline { 2 - 3 } $\begin{array}{l}\text { Decrease in } \\
\text { perfused leg }\end{array}$ & $\begin{array}{l}>5 \mathrm{y} \\
(\mathrm{n}=14)\end{array}$ & $\begin{array}{c}<5 \mathrm{y} \\
(\mathrm{n}=8)\end{array}$ & $P$ value \\
\hline ABI & $13(93 \%)$ & $4(50 \%)$ & .024 \\
PI femoral & $13(93 \%)$ & $4(50 \%)$ & .024 \\
PI popliteal & $12(100 \%)^{a}$ & $7(88 \%)$ & .221 \\
\hline
\end{tabular}

ABI, ankle-brachial index; PI, pulsatility index.

${ }^{a} \mathrm{n}=12$; data for two patients were not available.

ative site does not allow insertion of the cannulas at the same level. All patients in this study underwent only one ILP.

Long-term effects after ILP are mainly functional and consist of edema, stiffness, functional impairment, and muscle atrophy. ${ }^{21-23}$ Late vascular morbidity after ILP without EBRT has not been previously mentioned in other studies. In our study, one partial arterial occlusion $(3 \%)$ was found. In contrast, long-term effects of EBRT have extensively been described in the literature. In a study of Butler et al., ${ }^{12}$ three types of vascular damage have been described. At first, thrombosis occurs within 5 years after EBRT; a second fibrotic occlusion is seen within 10 years; and finally, a predisposition to the development of atheroma together with periarterial fibrosis is associated with a latent interval of 20 or more years. Rijbroek et al. ${ }^{24}$ mention claudication after a latent period. This is masked by the other effects such as pain, functional impairment, and edema. According to Kalman et al., ${ }^{13}$ long-term vascular side effects of EBRT resemble the natural process of atherosclerosis, which is a combination of direct damage, periarterial fibrosis, and occlusion of vasa vasorum. The EBRT accelerates this process, sometimes 10 to 27 years after treatment. Little is known about the combined effects of ILP and EBRT. Vrouenraets et al. ${ }^{22}$ described one brachial arterial occlusion, but this was only 4 months after treatment. Olieman et al. ${ }^{16}$ described the occurrence of necrosis after ILP but did not find any increased tumor-related morbidity after ILP followed by EBRT. In another series, ILP was performed after EBRT, but it did not lead to more local toxicity or complications. ${ }^{25}$

In our study, amputation was performed in nine patients $(23 \%)$. This is higher than the $9 \%$ to $21 \%$ described in the literature. ${ }^{4,26,27}$ However, amputations due to long-term complications like critical leg ischemia, which was performed in two patients (5.1\%), have not been described in other studies. Furthermore, three complete $(9 \%)$ and one partial (3\%) arterial occlusion were found after the combined procedure.

Fortunately, these patients did not have invalidating symptoms of arterial occlusive disease. In most cases, vascular pressure measurements and duplex ultrasonographic evaluation showed statistically lower values compared with the contralateral extremity, but these were still within the normal range. This could explain the absence of symptoms.

The PI value normally increases progressively from aorta to ankle. A decrease in PI indicates stenosis in a more proximal vascular segment. ${ }^{28}$ In our study, six of seven patients with an abnormal femoral PI underwent iliac perfusion. This implies a vascular reaction at the level of cannulation. Furthermore, seven patients showed a decrease in popliteal PI compared with the femoral PI, which implies that vascular damage is present at a more proximal (i.e., cannulation or resection) level. However, with the present data, it is not possible to support this thesis because of the relatively small study population, and the absence of symptoms and other abnormal outcomes of the vascular work-up.

It is important to realize that blood vessels lose their elasticity with the years and are subject to the normal process of atherosclerosis. Furthermore, unilateral peripheral arterial occlusive disease is common. However, the fact that lower rates of ABI and PI were found in the treated leg in almost all 
patients and that no marked difference was found between younger and older patients makes the assumption of treatment-induced differences plausible.

Because only four patients with a lower leg STS were not treated with adjuvant EBRT, there are still no clinically relevant data about the late vascular damage of the single procedure of ILP. Thijssens et al. ${ }^{29}$ showed that adjuvant EBRT seems beneficial in all patients, so it might be impossible to evaluate the sole effects of ILP on the vascular system in the future.

Major late vascular complications after the combined procedure, like critical leg ischemia necessitating amputation, were found in two patients in this study. One patient had no risk factors for peripheral arterial occlusive disease besides smoking. He had had intermittent claudication 8 years after ILP and EBRT, and a normal ABI of 1.09. His condition did not improve after 2 years of conservative therapy and reconstruction was impossible, so he underwent an amputation 125 months after the initial limb salvage treatment strategy. The second patient, who had diabetes mellitus and familial cardiovascular disease, experienced no complications the first few years after ILP and EBRT. After 6 years, she experienced a pathological proximal tibia fracture due to radiationinduced osteonecrosis in the previous surgically treated area and needed to wear a brace. She lived for 3 years with a disabling function impairment of the knee and then developed signs of critical leg ischemia. An upper leg amputation was performed 110 months after the initial treatment. She now walks with a wellfunctioning prothesis.

The importance of leg preservation has been mentioned before. Even though most patients still are satisfied with the initial limb-saving treatment that they underwent, amputations due to major late complications with severe morbidity make the rationale of limb salvage worth reconsidering.

Recently, one patient was successfully treated with thrombectomy for an acute popliteal artery occlusion. This patient, who underwent an ILP at femoral level followed by EBRT for a STS in the fossa poplitea 5 years before, had no complaints of peripheral arterial occlusive disease during his vascular work-up for this study 10 months earlier. ABI (1.03) and femoral PI (6.3) were normal; popliteal PI was low (5.3). With duplex ultrasonography, some atherosclerosis in the femoropopliteal section was seen. This patient has diabetes and hypertension, is obese (body mass index >30), and was a former smoker, so he was especially at risk for developing atherosclerosis.
This study shows that despite the importance of preventing major late vascular complications after the combined procedure of ILP and EBRT, a routine noninvasive vascular work-up does not seem to add value to normal follow-up. It is more important to realize that patients after the limb salvage treatment strategy of ILP, followed by delayed tumor resection and EBRT, are at risk for late vascular complications. This risk is substantially raised when personal risk factors such as smoking, diabetes, hypertension, obesity, and hypercholesterolemia are present. Because symptoms of vascular complications can be masked by the normal effects of the treatment itself, the possibility of vascular morbidity should be considered if the patient has any complaint. Furthermore, all patients must be convinced of the importance of reducing their additional personal risk factors for atherosclerosis.

In conclusion, objective measurements show a time-related decrease ( $>5$ years' follow-up) of ABI and femoral PI in the treated leg, usually without subjective complaints. ILP followed by delayed resection and EBRT for a locally advanced STS can lead to major late vascular morbidity that requires amputation.

\section{REFERENCES}

1. Rosenberg SA, Tepper J, Glatstein E, et al. The treatment of soft-tissue sarcomas of the extremities: prospective randomized evaluations of (1) limb sparing surgery plus radiation therapy compared with amputation and (2) the role of adjuvant chemotherapy. Ann Surg 1982; 196:305-15.

2. Hoekstra HJ, Schraffordt Koops H, Oldhoff J. Soft tissue sarcoma of the extremity. Eur J Surg Oncol 1994; 20:3-6.

3. Singer S, Demetri GD, Baldini EH, Fletcher DM. Management of soft-tissue sarcomas: an overview and update. Lancet Oncol 2000; 1:75-85.

4. Eggermont AM, Schraffordt Koops H, Lienard D, et al. Isolated limb perfusion with high-dose tumor necrosis factor-alpha in combination with interferon-gamma and melphalan for nonresectable extremity soft tissue sarcomas: a multicenter trial. J Clin Oncol 1996; 14:2653-65.

5. Van Ginkel RJ, Thijssens KJM, Pras E, van der Graaf WTA, Suurmeijer AJH, Hoekstra HJ. Isolated limb perfusion with TNF and melphalan for locally advanced soft tissue sarcoma: Three time periods at risk for amputation. Ann Surg Oncol 2007 January 26; [Epub ahead of print].

6. Renard N, Lienard D, Lespagnard L, Eggermont AMM, Heimann R, Lejeune FJ. Early endothelium activation and polymorhonuclear cell invasion precede specific necrosis of human melanoma and sarcoma treated by intravascular highdose tumour necrosis factor alpha (rTNFa). Int J Cancer 1994; 57:656-63.

7. Olieman AFT, van Ginkel RJ, Hoekstra HJ, Mooyaart EL, Molenaar WM, Schraffordt Koops H. Angiographic response of locally advanced soft-tissue sarcoma following hyperthermic isolated limb perfusion with tumor necrosis factor. Ann Surg Oncol 1997; 4:64-9. 
8. Bulman AS, Jamieson CW. Isolated limb perfusion with melphalan in the treatment of malignant melanoma. Br J Surg 1980; 67:660-2.

9. Klicks RJ, Vrouenraets BC, Nieweg OE, Kroon BBR. Vascular complications of isolated limb perfusion. Eur J Surg Oncol 1998; 24:288-91.

10. Eroglu A, Ozcan H, Ervavuz Y, Kocaglu H, Demirci S, Aytac SK. Deep venous thrombosis of the extremity diagnosed by color Doppler ultrasonography after isolated limb perfusion. Tumori 2001; 87:187-90.

11. Piedbois P, Becquemin JP, Pierquin B, et al. Arterial stenosis after radiotherapy. Bull Cancer Radiother 1990; 77:3-13.

12. Butler MJ, Lane RH, Webster JH. Irradiation injury to large arteries. Br J Surg 1980; 67:341-3.

13. Kalman PG, Lipton IH, Provan JL, Walker PM, Miles JT, Yeung HP. Radiation damage to large arteries. Can J Surg 1983; 26:88-91.

14. McCready RA, Hyde GL, Bivins BA, Mattingly SS, Griffen WO Jr. Radiation induced arterial injuries. Surgery 1983; 93:306-12.

15. Van Ginkel RJ, Limburg PC, Piers DA, Schraffordt Koops H, Hoekstra HJ. Value of continuous leakage monitoring with radioactive iodine-131-labeled human serum albumin during hyperthermic isolated limb perfusion with tumor necrosis factor-alpha and melphalan. Ann Surg Oncol 2002; 9:355-63.

16. Olieman AFT, Pras E, van Ginkel RJ, Molenaar WM, Schraffordt Koops H, Hoekstra HJ. Feasibility and efficacy of external beam radiotherapy after hyperthermic isolated limb perfusion with $\mathrm{TNF} \alpha$ and melphalan for limb-saving treatment in locally advanced extremity soft-tissue sarcoma. Int $J$ Radiat Oncol Biol Phys 1998; 40:807-14.

17. Coindre JM, Trojani M, Contesso G, et al. Reproductability of a histopathologic grading system for adult soft tissue sarcoma. Cancer 1986; 58:306-9.

18. AJCC Cancer Staging Manual. New York: Springer Verlag, 2002.

19. Klein ES, Walden R, Ben-Ari GY. Peripheral blood flow studies following isolated limb perfusion with cisplatin. Reg Cancer Treat 1993; 3:137-9.

20. Muchmore JH, Krementz ET, Kerstein MD. Noninvasive evaluation of peripheral vasculature following regional hyper- thermic chemotherapeutic perfusion (RHCP). Am Surg 1987; 53:94-6.

21. Noorda EM, Vrouenraets BC, Nieweg OE, van Coevorden F, van Slooten G, Kroon BB. Isolated limb perfusion with tumor necrosis factor- $\alpha$ and melphalan for patients with unresectable soft tissue sarcoma of the extremities. Cancer 2003; 98:1483-90.

22. Vrouenraets BC, Keus RB, Nieweg OE, Kroon BB. Complications of combined radiotherapy and isolated limb perfusion with tumor necrosis factor alpha \pm interferon gamma and melphalan in patients with irresectable soft tissue tumors. $J$ Surg Oncol 1997; 65:88-94.

23. Olieman AFT, Schraffordt Koops H, Geertzen JHB, Kingma J, Hoekstra HJ, Oldhoff J. Functional morbidity of hyperthermic isolated regional perfusion of the extremities. Ann Surg Oncol 1994; 1:382-8.

24. Rijbroek A, Vermeulen EG, Slotman BJ, Wisselink W, Rauwerda JA. Radiation-induced arterial disease. Ned Tijdschr Geneeskd 2000; 144:353-6.

25. Lans TE, Grünhagen DJ, de Wilt JHW, van Geel AN, Eggermont AMM. Isolated limb perfusions with tumor necrosis factor and melphalan for locally recurrent soft tissue sarcoma in previously irradiated limbs. Ann Surg Oncol 2005; 12:40611.

26. Lejeune FJ, Pujol N, Liénard D, et al. Limb salvage by neoadjuvant isolated perfusion with $\mathrm{TNF} \alpha$ and melphalan for non-resectable soft tissue sarcoma of the extremities. Eur $J$ Surg Oncol 2000; 26:669-78.

27. Gutman M, Inbar M, Lev-Shlush D, et al. High dose tumor necrosis factor- $\alpha$ and melphalan administered via isolated limb perfusion for advanced limb soft tissue sarcoma results in a $>90 \%$ response rate and limb preservation. Cancer 1997; 79:1129-37.

28. Kitslaar PJEHM. Doppler ultrasound tests in the diagnosis of chronic aortoiliac obstruction. Neth J Surg 1982(Suppl 2):659.

29. Thijssens KJM, van Ginkel RJ, Pras E, Suurmeijer AJH, Hoekstra HJ. Isolated limb perfusion with tumor necrosis factor $\alpha$ and melphalan for locally advanced soft tissue sarcoma: the value of adjuvant radiotherapy. Ann Surg Oncol 2006; 13:1-7. 